\title{
Phosphonate applied as a pre-plant dip controls Ceratocystis paradoxa base rot of pineapple planting material
}

\author{
J. M. Anderson ${ }^{1,2} \oplus$. J. R. Dean $^{2} \cdot$ K. G. Pegg ${ }^{2}$
}

Received: 3 August 2021 / Accepted: 18 January 2022 / Published online: 21 February 2022

(c) The Author(s) 2022

\begin{abstract}
Base rot, caused by Ceratocystis paradoxa, can be a severe disease of pineapple planting material and can result in poor establishment of plants. Pre-plant dipping of pineapple crowns in potassium phosphonate is used to control Phytophthora cinnamomi root and heart rot and was tested for efficacy against base rot in this study. Dipping crowns in $0.5 \%$ potassium phosphonate for 2 min significantly reduced the severity of base rot on inoculated crowns in two trials with 'MD2' and '73-50'. Fresh crowns had a more marked response to potassium phosphonate than well-cured, dried crowns. In studies with amended media, the growth of $C$. paradoxa was not inhibited by phosphonate concentrations of up to $100 \mathrm{ppm}$. Growth was reduced at higher concentrations but phosphonate did not completely inhibit growth of $C$. paradoxa even at the highest rate of 6000 ppm. Potassium phosphonate failed to control incidental Penicillium funiculosum infection of basal crown tissue.
\end{abstract}

Keywords Ananas comosus $\cdot$ Chalara paradoxa $\cdot$ Butt rot $\cdot$ Potassium phosphonate

Base or 'butt' rot of pineapple (Ananas comosus) caused by Ceratocystis paradoxa (Dade) C. Moreau can be a serious disease of pineapple planting material (Rohrbach and Johnson 2003). Pineapples may be propagated from crowns (apical vegetative shoots), slips (lateral vegetative shoot from the peduncle below the fruit) and suckers (axillary vegetative shoot) (Rohrbach and Schmitt 2003). C. paradoxa can rot the entire piece of planting material and affected pieces are usually discarded by growers. However, where there is partial decay of the base (butt), the material may not be discarded and when planted growth will be severely curtailed due to reduced carbohydrate reserves in infected stems and the destruction of some root initials (Rohrbach and Johnson 2003). Infection occurs through wounds produced when planting materials are removed from the mother plant. Allowing wounds to heal and suberise (cure) by storing on mother plants in the field during dry weather provides good control of the disease (Rohrbach and Johnson 2003). However, mechanisation in the pineapple industry has increased the pace of farm operations meaning

$\triangle$ J. M. Anderson

jay.anderson@scu.edu.au

1 The Centre for Organics Research, Southern Cross University, Lismore, NSW 2480, Australia

2 Department of Agriculture and Fisheries, Ecosciences Precinct, Brisbane, QLD 4102, Australia freshly removed planting material is planted with no time for curing. C. paradoxa can survive in the soil as chlamydospores in decaying pineapple trash and if uncured or untreated material is planted in infested soils losses can be extremely high Rohrbach and Johnson (2003). Freshly removed planting material for immediate planting must be treated with a suitable fungicide within $12 \mathrm{~h}$ of removal from the mother plant to avoid base rot (Rohrbach and Johnson 2003). Overseas, these fungicides have included benomyl or triadimefone (Rohrbach and Johnson 2003), while in Australia propiconazole is registered for use as a pre-plant dip (Australian Pesticides and Veterinary Medicines Authority 2021).

Anderson et al. (2012) found that a pre-plant dip of pineapple planting material in $0.5 \%$ potassium phosphonate reduced Phytophthora cinnamomi root and heart rot by $80-100 \%$ in a series of experiments with the pineapple cultivars Smooth Cayenne, MD2 and 73-50. Originally phosphonate was considered to only have activity against diseases caused by Oomycetes, but it has an effect against a much wider spectrum of diseases (Heaton and Dullahide 1990; Guest and Grant 1991; Guest et al. 1995; Norman et al. 2006). Rohrbach and Schenck (1985) when evaluating the effectiveness of phosphonate fungicides in Hawaii for the control of Phytophthora root and heart rot of pineapple, found that fosetyl-Al (also a phosphonate product) as a pre-plant dip at 1200 and $2400 \mathrm{ppm}$ 
significantly reduced base rot of pineapple crowns caused by C. paradoxa.

In this study the activity of potassium phosphonate in vitro against $C$. paradoxa was investigated, as was the effectiveness of potassium phosphonate as a dip treatment of crowns for the control of base rot caused by C. paradoxa.

A phosphonate sensitivity test for $C$. paradoxa (isolate BRIP 53417) was conducted on corn meal agar (CMA) amended with potassium phosphonate concentrations of: 0 , $1,10,50,100,500,1000,2000,4000,5000$ and $6000 \mathrm{ppm}$ active ingredient (a.i.). Plates were made using the method as described in Anderson et al. (2012). A 3 mm plug from a 4-day old culture on potato dextrose agar (PDA) was used to initiate cultures. Three single plate replicates were used for each concentration. Colony diameter measurements were made (subtracting $3 \mathrm{~mm}$ for the plug) and the daily growth rate for the three plates were averaged and compared by analysis of variance (Genstat $19^{\text {th }}$ Edition).

Three experiments were conducted to examine the effect of phosphonate dipping on the colonisation of C. paradoxa on the base of inoculated crowns. Prior to treatment crowns were sliced across the base to expose a fresh surface before either: 1) dipping in $0.5 \% \mathrm{v} / \mathrm{v}$ a.i. potassium phosphonate $\left(0.5 \% \mathrm{w} / \mathrm{v}, \mathrm{pH} 6.5\right.$, Agri-Fos $600^{\circledR}$, Agrichem, Australia) for 2 min before drying for $24 \mathrm{~h} ; 2$ ) inoculation with conidia of C. paradoxa, or; 3 ) both dipping in potassium phosphonate and inoculation with conidia (Table 1). The $C$. paradoxa inoculum was made by flooding approximately 2 -weekold PDA cultures with sterile water, gently dislodging conidia, filtering through 4 layers sterile gauze and adjusting concentration with sterile water as required to either $1 \times 10^{4}$ or $1 \times 10^{6}$ conidia/mL (Table 1 ). Conidia were applied to the exposed bases of the crowns using a hand-held atomiser ensuring even application. Crowns were stored up-side-down with the cut bases exposed in high humidity (approx. 80\%) (Fig. 1) for 5 days prior to removal for visual assessment. Assessments were made by cutting vertically through crowns and rating base rot severity on a 5-point scale. Data were analysed using ANOVA (Genstat 19th Edition) except for experiment 2 where the normality assumption underlying ANOVA was not met and therefore a Kruskal-Wallis (Genstat 19th Edition) test was applied.

In the in vitro experiment there was some inhibition of mycelial growth of $C$. paradoxa at potassium phosphonate concentrations greater than $100 \mathrm{ppm}$ (Table 2). Increased concentrations gave greater inhibition but growth was not totally inhibited at concentrations tested. The $5000 \mathrm{ppm}$ rate is equivalent to the pre-plant dip concentration.

Dipping the crowns in potassium phosphonate decreased the base rot incidence and severity after inoculation with $C$. paradoxa (Table 3, Fig. 1). In the first experiment with fresh crowns the pre-inoculation phosphonate dip reduced disease incidence from $55 \%$ down to $0 \%$ in crowns inoculated with $1 \times 10^{4}$ conidia/mL, and from $100 \%$ down to $5 \%$ in crowns inoculated with $1 \times 10^{6}$ conidia/mL (Table 3). Disease was more severe at the higher inoculum concentration in the nondipped crowns (Table 3 ).

The second experiment (MD2, December 2011) was undertaken with aged and well cured crowns which had been dried on the mother plants in the field with good air

Table 1 Summary of experiments undertaken to examine effect of phosphonate dip on base rot caused by C. paradoxa

\begin{tabular}{|c|c|c|c|}
\hline Experiment information & Experiment 1 & Experiment 2 & Experiment 3 \\
\hline \multicolumn{4}{|l|}{ Source of planting material } \\
\hline Cultivar & $' 73-50 ’$ & 'MD2' & 'MD2' \\
\hline Location & Beerwah, South East Queensland & $\begin{array}{l}\text { Beerwah, South } \\
\text { East Queensland }\end{array}$ & Mareeba, North Queensland \\
\hline Date & September, 2010 & December, 2011 & February, 2012 \\
\hline Plant part & Crown & Crown & Crown \\
\hline Replicates & 20 fresh crowns per treatment & $\begin{array}{l}6 \text { well cured } \\
\text { crowns per } \\
\text { treatment }\end{array}$ & $\begin{array}{l}20 \text { crowns per treat, harvested by } \\
\text { twisting leaving remnants of } \\
\text { fruit tissue }\end{array}$ \\
\hline \multicolumn{4}{|l|}{ Treatments } \\
\hline Non-dipped, non-inoculated control & $\checkmark$ & $\checkmark$ & $\checkmark$ \\
\hline Dipped, non-inoculated & $\checkmark$ & Not assessed & Not assessed \\
\hline Non-dipped, inoculated $1 \times 10^{4}$ conidia $/ \mathrm{mL}$ & $\checkmark$ & Not assessed & Not assessed \\
\hline Non-dipped, inoculated $1 \times 10^{6}$ conidia $/ \mathrm{mL}$ & $\checkmark$ & $\checkmark$ & $\checkmark$ \\
\hline Dipped, inoculated $1 \times 10^{4}$ conidia $/ \mathrm{mL}$ & $\checkmark$ & Not assessed & Not assessed \\
\hline Dipped, inoculated $1 \times 10^{6}$ conidia $/ \mathrm{mL}$ & $\checkmark$ & $\checkmark$ & $\checkmark$ \\
\hline $\begin{array}{l}\text { Inoculated } 1 \times 10^{6} \text { conidia/mL, } 24 \text { h later } \\
\text { dip in } 0.5 \% \text { phosphonate }\end{array}$ & Not assessed & $\checkmark$ & Not assessed \\
\hline Inoculation & \multicolumn{3}{|c|}{ Inoculum was applied $24 \mathrm{~h}$ after treatment unless stated otherwise } \\
\hline Incubation & \multicolumn{3}{|c|}{$\begin{array}{l}\text { After inoculation crown incubated at } 28{ }^{\circ} \mathrm{C} \text {, approximately } 80 \% \text { relative humidity for } 5 \text { days prior } \\
\text { to assessment }\end{array}$} \\
\hline
\end{tabular}


Fig. 1 Photograph of pineapple crowns inoculated with conidia and stored in high humidity to enable expression of base rot. Crowns on the left had been dipped in $0.5 \%$ potassium phosphonate prior to inoculation with $1 \times 10^{6}$ conidia/mL, crowns on the right received no treatment prior to inoculation
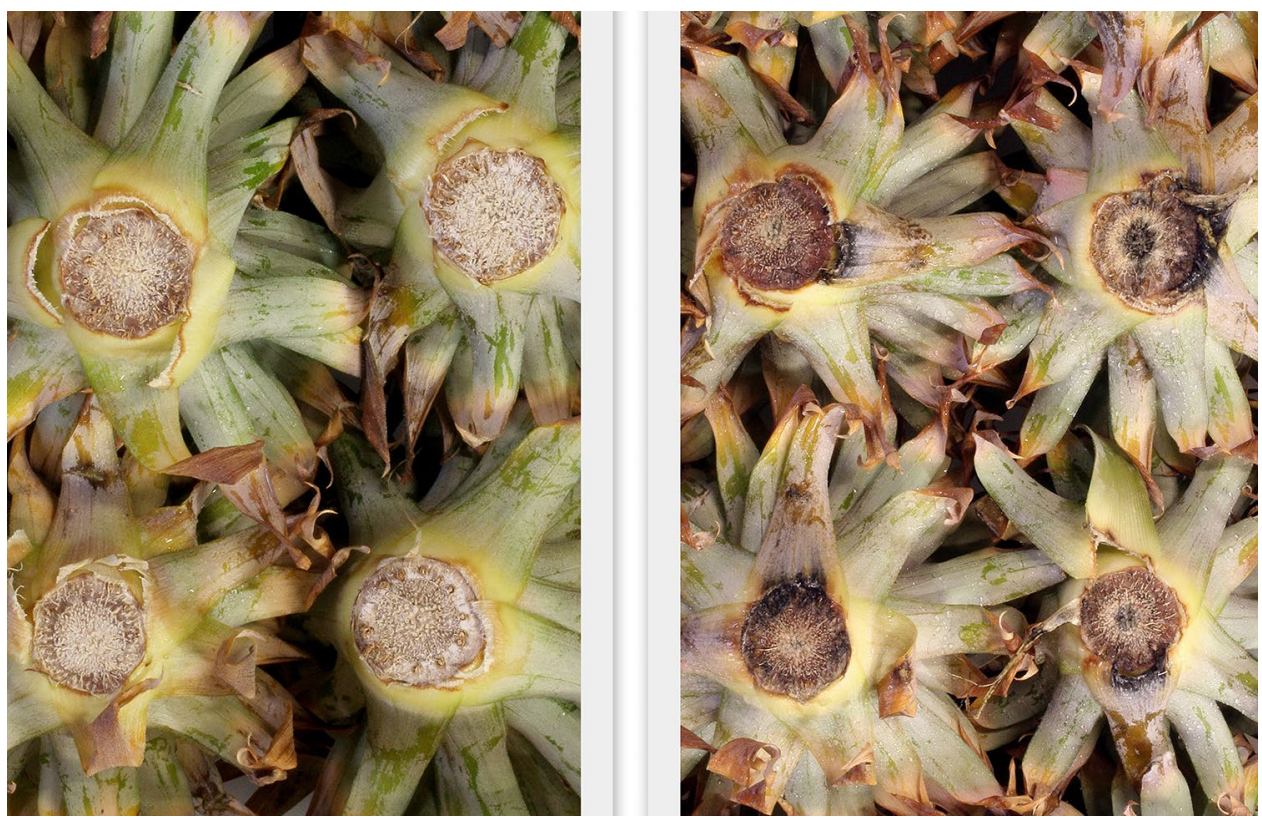

circulation, in dry conditions. In contrast to the first experiment, inoculation with conidia of $C$. paradoxa caused base rot in $100 \%$ of crowns which had been dipped in potassium phosphonate (Table 3). However, the pathogen did not infect the basal leaves of the potassium phosphonate dipped crowns (Table 3). Application of phosphonate $24 \mathrm{~h}$ after inoculation did not prevent destruction of stem or basal leaves by the pathogen (Table 3).

At the time of assessment of the third trial, there was a blue mould, visually distinct from the appearance of base rot, present on the bases of many of the crowns. The mould was identified as Penicillium funiculosum Thom by morphological methods. The base rot and blue mould were both

Table 2 Average daily growth rate of $C$. paradoxa growing on CMA amended with different concentrations of potassium phosphonate. Average daily growth rates followed by different letters indicate significant difference at $\mathrm{P}=0.05$

\begin{tabular}{ll}
\hline Phosphorous acid concentration (ppm) & $\begin{array}{l}\text { Average daily growth rate } \\
(\mathrm{mm})\end{array}$ \\
\hline 0 & $21.0 \mathrm{~g}$ \\
1 & $21.5 \mathrm{~g}$ \\
5 & $20.7 \mathrm{~g}$ \\
10 & $21.0 \mathrm{~g}$ \\
50 & $21.0 \mathrm{~g}$ \\
100 & $21.0 \mathrm{~g}$ \\
500 & $17.3 \mathrm{f}$ \\
1000 & $15.3 \mathrm{e}$ \\
2000 & $9.0 \mathrm{~d}$ \\
4000 & $4.2 \mathrm{a}$ \\
5000 & $7.2 \mathrm{c}$ \\
6000 & $6.0 \mathrm{~b}$ \\
\hline
\end{tabular}

assessed for incidence and severity. The P. funiculosum colonised the bases of the non-dipped, non-inoculated crowns (Table 3). The crowns which were inoculated with $C$. paradoxa had a $100 \%$ incidence of base rot and the symptoms were severe (Table 3). The crowns which had been dipped in potassium phosphonate and then inoculated had a mixture of base rot and blue mould (Table 3).

This experiment indicates that $P$. funiculosum can colonise and damage the cut stem of the hybrid 'MD2'. In the non-dipped crowns inoculated with $C$. paradoxa the rapid damage caused by $C$. paradoxa masked the presence of $P$. funiculosum. The phosphonate dip treatment failed to reduce the incidence and severity of stem decay caused by $P$. funiculosum. The crowns used in this study had been harvested by twisting the crowns to remove them from the fruit (usual practice is to cut across the stem), leaving a portion of fruit tissue attached to the crown which was invaded by the fungus prior to trimming before treatment and inoculation.

In this experiment, when the crowns were examined with a hand lens it was found that they were infested with red mite which had caused damage when feeding on the white basal tissue of the lower leaves. When isolations were made from these feeding sites, $P$. funiculosum was recovered from all lesions. This indicates that these feeding sites had provided an entry wound for P. funiculosum which sporulated prolifically to provide inoculum for the cut stem of the crowns. Where P. funiculosum is present growers may need to invest in treatment with compatible fungicides or use cutting, rather than twisting, to remove crowns to prevent this occurring and affecting plant establishment.

Rohrbach and Schenck (1985) using 2\% V-8 juice as a substrate in an in vitro study, found that fosetyl -Al and phosphorous acid at rates of $1200 \mathrm{ppm}$ and $2400 \mathrm{ppm}$ inhibited growth 
Table 3 Effect of potassium phosphonate on the incidence and mean severity of base rot caused by C. paradoxa in crowns of pineapple hybrids

\begin{tabular}{|c|c|c|c|c|c|c|c|c|}
\hline \multirow[b]{2}{*}{ Treatment } & \multicolumn{2}{|c|}{ 73-50 Sept 2010} & \multicolumn{2}{|c|}{ MD2 Dec 2011} & \multicolumn{4}{|c|}{ MD2 Feb 2012} \\
\hline & $\begin{array}{l}\text { Base rot } \\
\text { Incidence }\end{array}$ & Severity ${ }^{\mathbf{A}}$ & $\begin{array}{l}\text { Base rot } \\
\text { Incidence }\end{array}$ & Severity ${ }^{B}$ & $\begin{array}{l}\text { Base rot } \\
\text { Incidence }\end{array}$ & Severity & $\begin{array}{l}\text { Blue mould } \\
\text { Incidence }\end{array}$ & Severity $^{\mathrm{C}}$ \\
\hline Non-dipped, non-inoculated control & $0 / 20$ & $0.00 \mathrm{a}$ & $0 / 6$ & $0 \mathrm{a}$ & $0 / 20$ & $0 \mathrm{a}$ & $19 / 20$ & 38.5 \\
\hline Dipped, non-inoculated & $0 / 20$ & $0.00 \mathrm{a}$ & n.a & n.a & n.a & n.a & n.a & n.a \\
\hline Non-dipped, inoculated $1 \times 10^{4} \mathrm{conidia} / \mathrm{mL}$ & $11 / 20$ & $0.59 \mathrm{~b}$ & n.a & n.a & n.a & n.a & n.a & n.a \\
\hline Non-dipped, inoculated $1 \times 10^{6}$ conidia $/ \mathrm{mL}$ & $20 / 20$ & $3.36 \mathrm{c}$ & $6 / 6$ & $5 \mathrm{~b}$ & $20 / 20$ & $4.65 \mathrm{c}$ & $-\dagger$ & $-\dagger$ \\
\hline Dipped, inoculated $1 \times 10^{4}$ conidia $/ \mathrm{mL}$ & $0 / 20$ & $0.00 \mathrm{a}$ & n.a & n.a & n.a & n.a & n.a & n.a \\
\hline Dipped, inoculated $1 \times 10^{6}$ conidia $/ \mathrm{mL}$ & $1 / 20$ & $0.003 \mathrm{a}$ & $6 / 6$ & $2 \mathrm{ab}$ & $6 / 20$ & $0.35 \mathrm{~b}$ & $20 / 20$ & 29.0 \\
\hline $\begin{array}{l}\text { Inoculated } 1 \times 10^{6} \text { conidia } / \mathrm{mL}, 24 \mathrm{~h} \text { later } \\
\text { dip in } 0.5 \% \text { phosphonate }\end{array}$ & n.a & & $6 / 6$ & $5 \mathrm{~b}$ & n.a & n.a & n.a & n.a \\
\hline $\mathrm{P}(1 . \mathrm{s} . \mathrm{d})$ & & $<0.001$ & & $<0.001$ & & $<0.001$ & & 0.089 \\
\hline
\end{tabular}

n.a. $=$ not assessed, Severity was assessed as $0=$ no infection; $1=$ slight colonisation of cut stem; $2=$ complete colonisation of cut stem; $3=$ complete colonisation of cut stem + one basal leaf; $4=$ complete colonisation of cut stem + one to three basal leaves; $5=$ complete colonisation of cut stem + all basal leaves

A Mean severity for each treatment (not including controls) were compared using ANOVA Genstat 19th Edition, data were square root transformed, back transformed means are presented

${ }^{B}$ As underlying assumption of normality for an ANOVA was not met a Kruskal-Wallis test was applied and a Bonferroni adjustment undertaken to enable multiple comparisons in $\mathrm{R}$

${ }^{\mathrm{C}}$ blue mould severity was assessed as percentage stem invasion

${ }^{\dagger}$ base rot extensive and any blue mould symptoms were obscured

of $C$. paradoxa (no growth at $2400 \mathrm{ppm}$ ) and attributed base rot control solely to the fungitoxic activity of the chemicals. In the current study where CMA was used as the substrate there was considerable growth at $5000 \mathrm{ppm}$ potassium phosphonate. It is possible that the isolate of $C$. pardoxa used in these studies is less sensitive to phosphonate, there is no literature comparing a large collection of $C$. paradoxa isolates for sensitivity to phosphonate.

The dip treatment failed to control base rot of stem tissue in well cured crowns but it prevented infection of their basal leaves. Potentially the inoculum was taken up more effectively in the dried crowns, but potassium phosphonate has been shown to induce defence responses in a range of plant/pathogen systems (Dann and McLeod 2021). Further investigations to determine if a defence response is stimulated by potassium phosphonate application to crowns would be useful.

This study shows that a pre-plant dip treatment of fresh pineapple planting material with potassium phosphonate is effective for the control of base rot caused by $C$. paradoxa. As this treatment will also protect young plants against Phytophthora root and heart rot it will help prevent irregular establishment of a new planting.

Acknowledgements This project was funded by Horticulture Australia Limited, using the pineapple research and development levy and contributions from the Australian Government. We thank Carole Wright for assistance with statistical analysis. An anonymous reviewer is acknowledged for improvements to the manuscript. We acknowledge our wonderful colleague $\mathrm{Mr} \mathrm{Col} \mathrm{Scott} \mathrm{(deceased)} \mathrm{who} \mathrm{helped} \mathrm{us}$ develop and undertake this work with a focus on practical outcomes for pineapple growers.

Author contributions K.P. and J.A. contributed to the study conception, design and analysis. Material preparation and data collection were performed by K.P., J.D. and J.A. Data analysis was performed by J.A. The first draft of the manuscript was written by K.P. and all authors commented on previous versions of the manuscript. All authors read and approved the final manuscript. Mr Col Scott contributed significantly to the work but passed away prior to paper submission.

Funding Open Access funding enabled and organized by CAUL and its Member Institutions.

Data availability The datasets generated and analysed during the current study are available from the corresponding author on reasonable request.

\section{Declarations}

Conflict of interest The authors declare that they have no conflict of interest.

Open Access This article is licensed under a Creative Commons Attribution 4.0 International License, which permits use, sharing, adaptation, distribution and reproduction in any medium or format, as long as you give appropriate credit to the original author(s) and the source, provide a link to the Creative Commons licence, and indicate if changes were made. The images or other third party material in this article are included in the article's Creative Commons licence, unless indicated otherwise in a credit line to the material. If material is not included in the article's Creative Commons licence and your intended use is not permitted by statutory regulation or exceeds the permitted use, you will 
need to obtain permission directly from the copyright holder. To view a copy of this licence, visit http://creativecommons.org/licenses/by/4.0/.

\section{References}

Anderson JM, Pegg KG, Scott C, Drenth A (2012) Phosphonate as a pre-plant dip controls Phytophthora cinnamomi root and heart rot in susceptible pineapple hybrids. Australas Plant Pathol 41:59-68. https://doi.org/10.1007/s13313-011-0090-6

Australian Pesticides and Veterinary Medicines Authority (2021) Public Chemical Registration https://portal.apvma.gov.au/home Information System Search Accessed 26 Oct 2021

Dann E, McLeod A (2021) Phosphonic acid: a long-standing and versatile crop protectant. Pest Manag Sci 77:2197-2208. https://doi. org/10.1002/ps.6156

Guest D, Grant B (1991) The complex action of phosphonates as antifungal agents. Biol Rev 66:159-187. https://doi.org/10.1111/j. 1469-185X.1991.tb01139.x

Guest DI, Pegg KG, Whiley AW (1995) Control of Phytophthora diseases of tree crops using trunk- injected phosphonates. In : Janick,
J. (Ed.) Horticultural Reviews. Volume 17: 299-330. John Wiley and Sons, Inc. https://doi.org/10.1002/9780470650585.ch9

Heaton JB, Dullahide SR (1990) Efficacy of phosphorous acid in other host pathogen systems. Australas Plant Pathol 19:133-134. https:// doi.org/10.1071/APP9900133

Norman DJ, Chen J, Yuen JMF, Mangravita- Novo A, Byrne D, Walsh L (2006) Control of bacterial of geranium with phosphorous acid. Plant Dis 90:798-808. https://doi.org/10.1094/PD-90-0798

Rohrbach KG, Johnson MW (2003) Pests, Diseases and Weeds In Bartholomew DP, Paull RE and Rohrbach (Eds) The Pineapple; Botany, Production and Uses. CABI Publishing, Wallingford. https://doi.org/10.1079/9780851995038.0000

Rohrbach KG, Schenck DP (1985) Control of pineapple heart rot, caused by Phytophthora parasitica and $P$. cinnamomi, with metalaxyl, fosetyl $\mathrm{Al}$ and phosphorous acid. Plant Dis 69:320. https:// doi.org/10.1094/PD-69-320

Rohrbach KG, Schmitt D (2003) Diseases of Pineapple In Ploetz RC $(E d)$ Diseases of Tropical Fruit Crops. CABI Publishing, Wallingford. https://doi.org/10.1079/9780851993904.0000 